\title{
Selecciones
}

\section{Las implicaciones éticas y bioéticas en la investigación científica}

Gloria Elena Estrada-Cely ${ }^{1} \mathrm{Mv}, \mathrm{PhD}$, Juan Pablo Parra-Herrera² Biólogo, cPhD

Fecha correspondencia:

Recibido: 8 de abril de 2016.

Aceptado: 5 de agosto de 2016.

Forma de citar:

Estrada-Cely GE, Parra-Herrera JP. Las implicaciones éticas y bioéticas en la investigación científica. Rev. CES Med. Zootec. 2016; Vol 11 (2): 115-118

Open access

(C) Copyright

Creative commons

Éthics of publications

Peer review

Open Journal System

e-ISSN 1900-9607

Sobre los autores:

${ }^{1}$ Docente Universidad de la Amazonía. Grupo de Investigación en Fauna Silvestre.

Comparte

\section{Introducción}

Las implicaciones éticas y bioéticas en el desarrollo de procesos de investigación científica, suponen dos tipos de consideraciones particulares, las de tipo intraespecífico, reconocidas por diversos autores del campo de la Bioética como bioética intraespecífica, microbioética o bioética deontológica, basada en el principio de igualdad y cuya prima facie de responsabilidad reposa en el respeto a la autonomía y la no maleficencia, dentro de las que se estructuran las relaciones entre los seres humanos o personas; y las de tipo interespecífico, constituida para las relaciones establecidas entre los seres humanos y las demás especies vivientes, basadas en el principio de desigualdad y guiadas por los principios de justicia y beneficencia desde la premisa del principio de responsabilidad, dado el superior carácter del ser humano en su condición único ser ético y moral 1. 2. 5. 6. ., q. 10.

\section{Implicaciones éticas y bioéticas intraespecíficas}

Las investigaciones que involucren seres humanos como participantes en experimentos, encuestas, entrevistas y estudios cualitativos, requieren un marco ético estricto que garantice la veracidad de los resultados y su legalidad, sin vulnerar los derechos y principios de los involucrados.

Como implicaciones éticas intraespecíficas generales se considera que todos los seres humanos nacen libres y con los mismos derechos, por lo que deben ser tratados con idéntico respeto, fraternidad y dignidad. Estos principios consignados en la Declaración Universal de los Derechos Humanos de 1948, deberán guiar la totalidad de investigaciones que impliquen seres humanos. En correspondencia con la Declaración de Helsinki de 1964 y los principios éticos universales, los participantes en una investigación tienen los siguientes derechos:

- Recibir información adecuada acerca de los objetivos, métodos, fuentes de financiamiento, posibles conflictos de intereses, afiliaciones institucionales del investigador, beneficios calculados, riesgos previsibles e incomodidades derivadas del experimento (según corresponda), estipulaciones post estudio y todo otro aspecto pertinente de la investigación.

- Ser informado del derecho de participar o no en la investigación y de retirar su consentimiento en cualquier momento, sin exponerse a represalias. Se debe prestar especial atención a las necesidades específicas de información de cada participante potencial, como también a los métodos utilizados para entregar la información. 
- Cuando se utiliza información suministrada por ellos o que involucra cuestiones individuales, su anonimato debe ser garantizado y observado por el investigador

- Tener la opción de ser informado sobre los resultados generales de la investigación.

- Para el caso de investigaciones médicas, ser informado de los aspectos de la atención que tienen relación con la investigación. La negativa del paciente a participar en una investigación o su decisión de retirarse no debe, bajo ningún motivo, afectar de manera adversa la relación médico-paciente.

Como garante de tales derechos, toda persona vinculada activamente con la investigación, una vez informada a satisfacción, deberá diligenciar y firmar un documento de consentimiento informado de participación; si el mismos no puede otorgarse por escrito, el proceso para lograrlo debe ser documentado y atestiguado formalmente. En todo caso, el investigador debe garantizar que el participante potencial no se encuentre bajo relación de dependencia o presión.

Para el particular caso de investigaciones que requieran la vinculación de participantes con incapacidad para otorga consentimiento informado, este debe ser solicitado a su representante legal. Este tipo de participantes no pueden ser admitidos en investigaciones que no tenga posibilidades de beneficio para el mismo, a menos que tenga como objetivo promover la salud del grupo representado por el participante potencial, no pueden realizarse en personas capaces de dar su consentimiento informado y la investigación implique sólo un riesgo y costo mínimos.

Cuando la investigación requiera la utilización de material o datos humanos identificables, como la investigación sobre material o datos contenidos en biobancos o depósitos similares, el investigador debe solicitar el consentimiento informado para la recolección, almacenamiento y reutilización; en los casos particulares de imposibilidad de obtención del mismo, sólo podrá realizarse con aval de un comité de ética de investigación.

\section{Implicaciones éticas y bioéticas interespecíficas}

En correspondencia con lo planteado por Estrada ${ }^{8}$, en la actualidad, y dada la fuerte tendencia antropomórfica otorgada al tema, las investigaciones que implican el uso de animales, suelen limitarse y en muchos casos sesgarse, hacia el otorgamiento de condiciones morales y éticas a los animales; sin embargo, y desde el referente filosófico abordado en esta investigación que corresponde al antropocentrismo débil o humanismo, se rechaza cualquier tipo de atribución de estatus moral para los animales, soportado además por los lineamientos deontológicos de las profesionales implicadas, desde las cual los animales son concebidos como medios para la satisfacción de necesidades humanas; vale la pena indicar que para cualquier tipo de uso se encuentra sujeto a cuestionamientos morales, éticos y bioéticos, particularmente orientados a su condición de seres emocionales y sintientes.

Desde una mirada política, la postura anteriormente presentada podría ubicarse en el contractualismo, que según Carruthers ${ }^{4}$, determina las normas morales como el resultado de contratos imaginarios entre humanos, pues la moral se define como un conjunto de normas que rigen las interacciones entre agentes, poniendo límites a los que pueden hacerse unos a otros, pero dejándoles la libertad para emprender sus 
propios planes y proyectos. Desde esta postura, el principio moral más fundamental del contractualismo es el respeto a la autonomía, condición no demandante por los animales dada su imposibilidad registrada para plantearse metas, actuar como agentes racionales libres y asumir responsabilidad morales, sino que se les podría otorgar dos variedades de importancia indirecta, una como derecho de propiedad de poblaciones humanas y otra como principio de interés de poblaciones humanas.

Un concepto importante a abordar en esta discusión, es el de agente racional autónomo. A pesar de las distintas intuiciones o aportes desde el campo de la etología animal, no se ha logrado verificar certeramente que los animales se comporten como seres racionales con un sistema de creencias, y que actúen en relación con ellas para satisfacer sus deseos, lo cual, según Carruthers ${ }^{4}$, es requisito fundamental para ser considerado un ser racional; concretamente, ningún animal parece ser capaz de hacer planes a largo plazo o de imaginar distintos futuros posibles, obrando en consideración a su sistema de creencias.

Como referente de consideración de uso de los animales como sujetos experimentales, se prestará especial atención a los parámetros formulados por Ressel y Burch $\frac{11}{1}$, en su libro "The principle of humane experimental technique" denominados las $3 R$ y que corresponden a:

- Reemplazar: sustituir el uso absoluto de animales por modelos informáticos; o relativo, por animales de baja percepción al dolor.

- Reducir: qué el número de animales utilizados sea el menor posible.

- Refinar: minimizar el dolor y la angustia de los animales objetos de investigación, manteniendo en todos los casos posibles, adecuados niveles de bienestar.

La totalidad de los preceptos anteriormente mencionados, además de los establecidas por autores de relevancia internacional para el tema como Cardozo y otros ${ }^{3}$, estructuran los cuestionamientos de análisis establecidos de manera general por los comités de ética, por lo que previo a la ejecución de investigaciones que involucren el uso de animales, y en correspondencia con la Ley 84 de 1989 "Estatuto Nacional para la Protección de los Animales", del Congreso de la República, resulta necesario solicitar aval de dicho comité, sujetando su desarrollo a las condiciones establecidas por el mismo.

El cumplimiento de la totalidad de los lineamientos éticos y bioéticos, inter e intraespecíficos, en la formulación y ejecución de investigaciones científicas, garantizan no solo la viabilidad legal de los procesos y metodologías contemplados en las mismas, sino además, la contribución directa al reforzamiento de sociedades respetuosas de lo vivo, su individualidad e importancia en el macro de la convivencia armónica como garantía de un mejor futuro.

\section{Bibliografía}

1. Beauchamp L., Childress F. Principios de Ética Biomédica. España: Masson. S.A, 1999. $522 \mathrm{p}$.

2. Beorlegui, C. Ética animal e idea de persona. 2005. [En línea] Madrid: Universidad Pontifica Comillas. Disponible desde internet en: http://goo.gl/uTTzGZ. 14 p. 
3. Cardozo C et al. El Animal Como Sujeto Experimental, Aspectos Técnicos Y Éticos. Chile: Universidad de Chile, Centro Interdisciplinarios de estudios en Bioética, CIEB. 2007. 288 p.

4. Carruthers, P. La cuestión de los animales - teoría de la moral aplicada. Gran Bretaña: Cambridge University press. 1995. 246 p.

5. Carmona J. et al. Macrobioética En: Colección Bios y Ethos. Bogotá: Kimpres. Universidad el Bosque, 1999. $13 \mathrm{p}$.

6. Capó-Marti, M. Aplicación de la bioética al bienestar y los derechos de los animales. España: Complutense SA. 2005. 112 p.

7. Cely, G. El horizonte bioético de las ciencias: Reflexiones para elaborar una ecoética. Bogotá: Fundación Cultural Javeriana, 2002 p 89-91.

8. Estrada, G. Bienestar animal en la Medicina Veterinaria y Zootecnia.2014. Florencia: Universidad de la Amazonía. Pp. 15 - 36

9. Engelhardt, H. Los fundamentos de la Bioética. Barcelona: Paidos, 1995. 545 p.

10. Hottois, G. ¿Qué es la Bioética? Bogotá: Universidad el Bosque, 2007. 21 p.

11. Russell W, Burch R. The Principles of Humane Experimental Technique. 1959. [En línea]. Baltimore: Johns Hopkins Bloomberg. 2011 Disponible desde internet en: http://goo.gl/JwMsP9. 